\title{
Knowledge among Women about the Method of Delivery in Albatool Teaching Hospital in Baquba City \\ Oras Zaki Saadoon $(\mathrm{BSc})^{1}$, Nadhim Ghazal Noaman $(\mathrm{PhD})^{2}$ and Moneam Akram Hassan (FIBMS) ${ }^{3}$
}

\begin{abstract}
Background: Most of the doctors interested in cesarean section and the techniques relate to these processes. This study aimed to assess the knowledge of women about the method of delivery in Albatool Teaching Hospital.

Objective: To study the preferred methods of delivery among women in relation to certain epidemiological criteria.

Patients and Methods: Across sectional study was conducted among women attending in Albatool teaching hospital including all the women from 1st January during March 2018. Results: Among 200 women who included in the study, $68.5 \%$ of them preferred the vaginal delivery while the rest preferred the cesarean delivery. In the same context, $57.2 \%$ of the age group below 20 years preferred cesarean delivery, while the age group above 20 years, preferred vaginal delivery with a percentage of more than $62.7 \%$. On the other hand, the opinions of the working women and housewife were preferred vaginal delivery with percentages $53 \%$ and $84 \%$ respectively.
\end{abstract}

Conclusion: The results indicated that most women tend to participate with their own doctor in decision-making on the type of delivery.

Keywords: Knowledge, Women, Mode of delivery.

Corresponding Author: orashad1111@gmail.com

Received: $15^{\text {th }}$ December 2019

Accepted: $3^{\text {th }}$ March 2020

DOI:https://doi.org/10.26505/DJM.18015081215

${ }^{1,3}$ Baquba Teaching Hospital - Diyala-Iraq
${ }^{2}$ College of Medicine-University of Diyala-Diyala -Iraq.

\section{Introduction}

Natural childbirth and its mechanism is so old, spontaneous; and it does not need any complex intervention. The development in medical technology contributed in reduction the numbers of the maternal and infant mortality rate. However improper use of these interventions without scientific and legal reasons has converted a normal delivery to the surgical and medical phenomenon[1]. The organizational models of public and private services vary, as do work relationships between healthcare professionals and treatment, which results in different hospital experiences for pregnant women[2]. 
Most women still prefer to have natural deliveries at governmental hospitals, and cesareans at private maternity clinics[3].

The increase in numbers of cesarean section concerns to many international organizations. World health organization declared that there are no justifying for any region to have a cesarean section more than $10-15 \%$ [4]. The cause of increased cesarean section rate is multi-factorial and the decision to deliver by cesarean section depends on a variety of factors including previous cesarean section, multiple gestations, malpresentation, fetal distress, failure of progress during labor and maternal medical conditions [5].

The sin of Eve, that was mentioned in Biblical book, influenced deeply in a brain of mankind "in pain shall you bring forth children"[6]. This belief makes pregnant women avoid pain and prefers the cesareans section.

Non-medical reasons also encourage pregnant women to prefer caesarean than normal labor. These reasons such as the pain of delivery, unsuitable time and date for this labor. In addition, there is an opinion says that the cesarean keep and protect the baby's brain[7].
The fast recovery after the natural delivery is the main reason that make pregnant women prefer this type of delivery than the cesarean section, in spite of there were recommendations in $47.5 \%$ from the medical side to choose the cesareans section[8].This study aimed to assess the knowledge of women about the mode of delivery. Aim of study: It aims to study knowledge of women in Baquba about the prefer method of delivery.

\section{Patients and Methods}

This study was conducted in Baquba Albatool teaching hospital as a crosssectional study started from the 1 st of January during March in 2018. Especial question includes (women's age, blood group, occupation, resident, number of parity, any complication during delivery, and what favorite type of delivery). Information was collected by the researcher during the interview with each woman.

\section{Statistical analysis}

Statistical analysis was done by computer and the data were analyzed by percentage, numbers and proportion.

\section{Results}

Table (1): Distribution of women according to the preferred type of delivery

\begin{tabular}{|l||c||c|}
\hline \hline \multicolumn{1}{|c||}{ Type of delivery } & N0. & $\%$ \\
\hline \hline Vaginal delivery & 137 & $68.5 \%$ \\
\hline \hline Cesarean delivery & 63 & $31.5 \%$ \\
\hline \hline Total & 200 & $100 \%$ \\
\hline
\end{tabular}

Depending on women's interview, majority of women $68.5 \%$ preferred vaginal delivery while a few numbers of women31.5\% preferred cesarean delivery. 
Table (2): Distribution of women according to their age and preferred type of delivery

\begin{tabular}{|l||l||c||c||c|c||}
\hline \multicolumn{1}{|c||}{ Age } & No. & Vaginal delivery & $\%$ & $\begin{array}{c}\text { Cesarean } \\
\text { delivery }\end{array}$ & $\%$ \\
\hline$<20$ & 14 & 6 & $42.8 \%$ & 8 & $57.2 \%$ \\
\hline $20-29$ & 75 & 47 & $62.7 \%$ & 28 & $37.3 \%$ \\
\hline $30-39$ & 70 & 50 & $71.4 \%$ & 20 & $28.6 \%$ \\
\hline$\geq 40$ & 41 & 34 & $82.9 \%$ & 7 & $17.1 \%$ \\
\hline \hline total & 200 & 137 & $68.5 \%$ & 63 & $31.5 \%$ \\
\hline
\end{tabular}

Depending on this table, the age group less than 20 years, $42.8 \%$ preferred vaginal delivery and other $57.2 \%$ preferred cesarean. The age group (20-29),62.7\% preferred vaginal delivery and other $37.3 \%$ preferred cesarean. The age group (30-39),71.4\% preferred vaginal delivery and the other
$28.6 \%$ preferred cesarean. The age group for more than 40 years, $82.9 \%$ preferred vaginal delivery and other $17.1 \%$ preferred cesarean. The total percentage in Table (2) proved that more than double of them preferred the vaginal delivery over cesarean delivery.

Table (3): Distribution of women according to the occupation in relation to the mode of delivery

\begin{tabular}{|l||c|c|c||c|c||}
\hline \multicolumn{1}{|c|}{ occupation } & No. & $\begin{array}{c}\text { Vaginal } \\
\text { delivery }\end{array}$ & $\%$ & $\begin{array}{c}\text { Cesarean } \\
\text { delivery }\end{array}$ & $\%$ \\
\hline \hline working & 83 & 53 & $63.8 \%$ & 30 & $36.1 \%$ \\
\hline \hline House wife & 117 & 84 & $71.7 \%$ & 33 & $28.3 \%$ \\
\hline \hline total & 200 & 137 & $68.5 \%$ & 63 & $31.5 \%$ \\
\hline
\end{tabular}

According to this table, the majority of women $71.7 \%$ preferred vaginal delivery official women $(63.8 \%)$ preferred vaginal while the other $28.3 \%$ preferred cesarean delivery while the $(36.1 \%)$ preferred cesarean delivery. delivery. And the majority of housewife

Table (4): Distribution of women according to their residency

\begin{tabular}{||l||c||c||c||c||c||}
\hline \multicolumn{1}{|c||}{ Residency } & No. & $\begin{array}{c}\text { Vaginal } \\
\text { delivery }\end{array}$ & $\%$ & $\begin{array}{c}\text { Cesarean } \\
\text { delivery }\end{array}$ & $\%$ \\
\hline \hline urban & 99 & 66 & $66.7 \%$ & 33 & $33.3 \%$ \\
\hline \hline rural & 101 & 71 & $70.3 \%$ & 30 & $29.7 \%$ \\
\hline \hline total & 200 & 137 & $68,5 \%$ & 63 & $31.5 \%$ \\
\hline
\end{tabular}

According to this table, the majority of of rural women $70.3 \%$ preferred vaginal urban women $66.7 \%$ preferred vaginal delivery and the other women $29.7 \%$ delivery while the other women $33.3 \%$ preferred cesarean delivery. preferred cesarean delivery. And the majority 
Table (5): Distribution of women according to the parity

\begin{tabular}{|l||c||c|c||c|c||}
\hline \multicolumn{1}{|c|}{ parity } & No. & $\begin{array}{c}\text { Vaginal } \\
\text { delivery }\end{array}$ & $\%$ & Cesarean delivery & $\%$ \\
\hline \hline Para1 & 40 & 25 & $62.5 \%$ & 15 & $37.5 \%$ \\
\hline \hline Para2 & 36 & 22 & $61.1 \%$ & 14 & $38.9 \%$ \\
\hline Para3 & 39 & 22 & $56.4 \%$ & 17 & $43.6 \%$ \\
\hline \hline Para4 and more & 85 & 68 & $80 \%$ & 17 & $20 \%$ \\
\hline \hline Total & 200 & 137 & $68.5 \%$ & 63 & $31.5 \%$ \\
\hline
\end{tabular}

Table (6): Distribution of the mother according the previous delivery complication

\begin{tabular}{||l||c||c||c||c||c||}
\hline obstetrics complication & No. & $\begin{array}{c}\text { Vaginal } \\
\text { delivery }\end{array}$ & $\%$ & $\begin{array}{c}\text { Cesarean } \\
\text { delivery }\end{array}$ & $\%$ \\
\hline \hline positive & 71 & 42 & $59.1 \%$ & 29 & $40.9 \%$ \\
\hline \hline negative & 129 & 95 & $73.6 \%$ & 34 & $26.4 \%$ \\
\hline \hline total & 200 & 137 & $68.5 \%$ & 63 & $31.5 \%$ \\
\hline
\end{tabular}

According to this table, $59.2 \%$ of women who have the previous complication preferred vaginal delivery while $40.8 \%$ preferred cesarean delivery. And decreased percent of preferred cesarean delivery $26.4 \%$ in previous non-complicated women while $73.6 \%$ preferred vaginal delivery.

\section{Discussion}

The sources of knowledge of these women, in this study, were from their relatives or friends; therefore they have the same Iraqi society knowledge. where, the traditional view here regard the vaginal delivery is best than cesarean section, because the time of healing after the vaginal delivery is less than a cesarean section. In addition to that, the society considers the cesarean section is a deviation from the normal way and accompanying bleeding risks and higher costs. Similar results were seen by Aali et al[9].

In developing countries, lower education level is responsible for poorer Knowledge of human reproduction than women in developed countries [1] The present study showed that $63.8 \%$ of occupational women preferred vaginal delivery while others preferred cesarean delivery. This Can be explained based on the fact that in Diyala, traditional Views in illiterate society prefer to have deliveries by indigenous ladies on the grounds of privacy.

This preference, according to some authors is related to those who could Not afford cesarean section But the present study revealed that the majority of women did not consider the economy as the factor for vaginal delivery over surgery [11]. In the present study, the majority of women $(68.5 \%)$ preferred vaginal mode of delivery because they believed that it enhances the affectionate relationship between mother and baby.

Women who preferred vaginal delivery generally felt that vaginal delivery is a natural and acceptable way of delivery and 
women who preferred cesarean delivery felt that CSs were safer and less painful. Similar findings were reported by Adageba et al in Ghana [12].

The association between maternal age and positive attitude towards CS in the current pregnancy, where $57.2 \%$ of studied women in younger age (less than 20) years had a positive attitude towards $\mathrm{CS}$ in the current pregnancy. This might be related to the belief in some families that young women at marriage have a small pelvis that is not suitable for vaginal delivery. However, older age groups showed a positive attitude towards vld in current pregnancy which goes with other studies in which advanced marital age is a contributing factor in increasing the $\mathrm{CS}$ rate. These findings are in agreement with Lin $\mathrm{HC}$ et al in Taiwan who reported that women younger than 25 years likely to request for CS delivery and those older than were more less likely to request for CS delivery [13].

The trending to the $\mathrm{CS}$ in current pregnancy was also related to; a number of previous CS, low educational levels of women's husbands and women having no children. These findings are close to those reported by Richard et al [14] study in Northern Ghana.

\section{Conclusions}

Most of pregnant women prefer vaginally, while the majority women that have shortage in knowledge or excessive fear wanted to undergo a cesarean sections. The reasons for cesarean delivery is a fear of labor pain. An important step in controlling the rising cesarean birth rate in developing countries is providing better information on pregnant women and their partners during the antenatal period about modes of Delivery, their indications, advantages, and adverse consequences.

\section{References}

[1]Jansen L, Gibson M, Bowles BC, Leach J. First do no harm: Interventions during childbirth. J Perinat Educ. 2013;22(2):83-92. [2]Saoji Ajeet, Nayse Jaydeep, Kasturwar Nandkishore, Relwani Nisha, Women's Knowledge, Perceptions, And Potential Demand Towards Caesarean Section; National Journal of Community Medicine; 2011 (2) 244-248.

[3]Fereshteh Zamani-Alavijeh, Parvin Shahry, Maryam Kalhori, and Marzieh Araba. Pregnant women's preferences for mode of delivery questionnaire: Psychometric properties. 2017 (6) 389-13. [4]Olajubu A Omobolanle, Olowokere, Adekemi, Adetona Tolulope ,Olowokere Idowu, Olajubu Oluwafemi . Acceptance of caesarean section among pregnant women in Nigeria;2018 (3)256-290.

[5]Fatemeh Ghotbi, Azadeh Akbari Sene, Eznollah Azargashb, Fakhrolmolouk Yassaee Women's knowledge and attitude towards mode of delivery and frequency of cesarean section on mother's request in six public and private hospitals in Tehran, Iran. 2014; (40)5. [6]Tahmina Begum,Cathryn Ellis, Malabika Sarker, Jean-Francois Rostoker, Aminur Rahman, Iqbal Anwar . A qualitative study to explore the attitudes of women and obstetricians towards caesarean delivery in 
rural Bangladesh; BMC Pregnancy and Childbirth 2018;210-21.

[7]Lei H, Wen SW, Walker M. Determinants of caesarean delivery among women hospitalized for childbirth in a remote population in China. J Obstet Gynaecol Can. 2003;25:937-43.

[8]Dias Michael Aziken, Lawrence OmoAghoja \& Friday Okonofua. Perceptions and attitudes of pregnant women towards caesarean section in urban Nigeria. Acta Obstetricia et Gynecologica. 2007; 86: 42-47 [9]Aali BS, Motamedi B. Women's knowledge and attitude towards modes of delivery in Kerman, Islamic Republic of Iran. Eastern Mediterran Health J. 2005;11(4):66372.

[10]Naithani U, Prerna B, Chauhan SS, Kumar D, Gupta S,Kirti. Knowledge, attitude and acceptance of antenatal women towards labor analgesia and cesarean section in a medical college hospital in India. J Obstet Anaesthesia Critical care. 2011;1(1):13-20. [11]Adageba R, Danso K, Adusu A \&Ankobea F. Awareness and Perceptions of and Attitudes towards Caesarean Delivery among Antenatal. Ghana Med J.2008;42(4):137-40.

[12]Adageba R, Danso K, Adusu A \&Ankobea F. Awareness and Perceptions of and Attitudes towards Caesarean Delivery among Antenatal. Ghana Med J.2008;42(4):137-40.

[13]Lin HC, Xirasagar S. Maternal age and the likelihood of a maternal request for cesarean delivery: A 5-year population based study. Am J Obstet Gynecol 2005; 192:848855.

[14]Richard Adongo Afaya, Victoria Bam , Felix Apiribu, Victor Atiah Agana Agani Afaya. Knowledge of Pregnant Women on Caesarean Section and their Preferred Mode of Delivery in Northern Ghana; An International Journal of Nursing and Midwifer;2018 (2) 451-477. 